\title{
Globalization in the post - colonial world
}

\author{
Larisa A. Korobeynikova \\ National Research Tomsk State University, 634050, Lenin Avenue, 36, Tomsk, Russia \\ National Research Tomsk Polytechnic University, 634050, Lenin Avenue, 30, Tomsk, Russia
}

\begin{abstract}
The paper presents a new interpretation of globalization within the boundaries of the author's concept of soft globalization, which exploits a normatively attractive alternative to the concept of the Empire. It is argued here that the conditions of development of contemporary post - colonial world communities do not require any unification in the form of the Empire, but instead the creation of a non repressive mechanism of social regulation - the implementation of a form of soft globalization, a globalization with a mental form are expedient here. Historically, globalization occurred in a strict material (i.e. economical and military) form that prompted the conditions for the evolution of civilization as the Empire: a case in which the development of the world occurs under the power of a single dominating state. Imperialistic politics leads to colonial politics formation. The history of the phenomena of civilization shows many instances of Empire globalization. Globalization in the Empire form was already observed at the time of the Roman Empire. At this time processes of development inside the Empire were manifestations of globalization in its highest cultural shape. But ancient Rome was also a social and political experiment that acquired the attributes of a purely material globalization in the end, and historically brought about the irreversible crash of the Roman Empire itself. Contemporary fluctuations referring to the process of globalization can be registered in the US's attempts of material domination inside this or that existing case of civilization, which causes colonialism appearance. The main idea stressed in the paper is that only a mental globalization could succeed in the end.
\end{abstract}

\section{Introduction}

The conditions of development of the present world community have changed in the last decades of world community development - since the end of the cold war. The new political situation requires to reflect on the post-colonial relations in contemporary world politics, which prima facie seem to move in the direction of democracy. Traditionally, democratic politics has been interpreted as an alternative to imperialistic politics, as a system of norms based on the principles of equality, freedom and non-violence. These principles set the main qualities of the political process, which produces the constant environment for the existence of social values and devices of life regulation. However, even within the boundaries of the democratic paradigm of politics, which exemplifies the principle of freedom in political practice, we can detect certain repressive mechanisms for the functioning of politics. The decision making process of a democratic society is not always able to eliminate conflicts of belief and values among its population, because the social agreement cannot be achieved by violent means. The conditions of development of contemporary diverse world communities do not require to refuse repressive mechanisms of political regulation, but to add a non-repressive mechanism of soft globalization to them, namely globalisation conceived in a mental form.

Presently globalization occurs in a strict material form, and this has both advantages and disadvantages. Advantages: for example, wide spread of modern forms of Western life in the world. Disadvantages: for example, cases of attempted globalization meet negative responses by several nations, ethnic and cultural minorities, religious confessions - all this sometimes brings phenomena of extremism and terrorism on the political scene. The development of globalization in a strict material form leads to the formation of Empires and colonial politics. An alternative to this is a soft form of globalization that could instead put the idea of a global citizenship under a new paradigm of democratic global citizenship at its centre. This could balance or harmonize global and local interests and values, generate equal opportunities for members of various nations, cultures, ethnic groups or minorities acting on the global civil arena.

This paper mainly deals with two dimensions characterizing the globalization process: a material

\footnotetext{
a Corresponding author: larisa_korobeynikova@rambler.ru
} 
dimension which leads to the appearance of Empires, and a mental dimension that presents an alternative to such imperialistic views: a set of principles inspiring a new type of democratic politics. In accordance with this, the first part of the paper will discuss some of the most relevant debates and topics concerned with the phenomenon of globalization. The second part of the paper will elaborate the concept of soft globalization. The main author's intuitions and reflections are summarized in the conclusion.

\section{Main Debates on the Issue of Globalization}

The discourse about globalization cannot be located inside one problem, it includes various dimensions, which extend the field of scientific knowledge and theoretical representation around the idea of globalization [1]. Such discursive approach can be characterized as an "intersectional approach to globalization". In most recent theoretical debates, depending on the character of the process of globalization (homogeneous or fragmentary), two trends of investigation of this process arise: (i) globalization on the basis of the idea of progress which leads to an homogeneous world (universalism); (ii) globalization on the basis of the representation of the world's real diversity (multiculturalism). Theorists of globalization stress the fact that an economic-homogenization paradigm of globalization is becoming powerful in both academic and popular usage. They then focus their attention on the increased integration of the global economy and its homogenizing effects on state policy and culture. As for the homogeneous (i.e. universalistic) discussions, the tendency for many issues to assume opposite values - on the segment comprising corporative versions of globalization and elite versions of globalization - arises. Even popular anti-globalist movements are nothing else but representations of the globalization process in alternative forms. Therefore, the contradictions associated with the process of globalization are not external with respect to such process, but instead integrated in it.

Multicultural concepts of globalization, based on the recognition of the world diversity, are popular because of their anti-repressive and tolerant form. Appraisals of multiculturalism as an intellectual trend, which could be evaluated as the core of recent multi-globalization processes, are controversial (as it is for example demonstrated in the works by authors like J. Searle, R. Rorty and C. Taylor) [2].

The theorists of globalization stress the fact that modern globalization processes include many instances of globalization. Here the author will mainly concentrate on four aspects concerning the process of globalization: political globalization, informational and net globalization.

Political theorists have been busy addressing the normative implication of globalization. Globalization is discussed in debates between cosmopolitans and communitarians. Cosmopolitanism has been developed on the universalistic values of modern moral and political thought. Communitarians deny the need to overcome international inequality, but often criticize the tendency of cosmopolitanism to defend global legal and political reforms. Attempts to achieve global justice are suspicious. Both cosmopolitans and communitarians discuss the prospects of democratic institutions at a global level. D. Held argues that globalization requires the extension of liberal democratic institutions. In contrast with D. Held, J. Habermas and other communitarians argue that democratic politics presupposes feelings of trust, commitment and belonging that remain uncommon at the transnational level [3].

The main problem about the interpretation of the community in a global era is investigated by means of the analysis of the relations among individuals, state and systems of states according to the principle of domestic analogy - i.e. analogy between international relations and domestic processes of a state. Relevant discussions here are also cantered on the interpretation of an isolated individual passing through a national state so that to arrive to a global state. The problem of what is global, then, is formulated in different terms. Legal conceptualism sees legal regulations imperatives behind the problem of the global, because the community is developed from natural states towards a separate political community. Another point of view puts into focus the idea of global responsibility generated by the global nature of the searched goals. Given all these considerations, political philosophy is expecting for the future a responsible community or 'good' society.

Some theorists consider contemporary globalization as a process of global-net community formation. Heterogeneity and complicated structures of the net provide a ground for various theoretical approaches in different fields of knowledge (Economics, Sociology, Social Psychology, Biology, etc.). The different nature of the materials, one finds on the net, stimulates the investigation of the net with respect to various disciplines and leads to a plurality of scientific positions. New trends concerning the investigation of the net have come on the scene very quickly due to the complicated nature of the net.

M. Castels stresses the fact that the network international platform has its own cultural interpretational model, which influences the character of the social evolution. Given certain conditions of change, it constitutes the main type of communication. Therefore, a new scientific and ordering paradigm has indeed appeared, and the notion of "net" has taken an universalistic dimension.

J. Habermas takes the openness of a net as one of its fundamental characteristics, something that gives rise to heterogeneous communicational connections and the spontaneous character of the constant change of its structure. The term "openness" is interpreted in many different ways: as i) openness of net elements with respect to the relations among each element of the net; as ii) absence of inner borders between the parts of the net; and as iii) openness of borders with respect to external environments. The net, thus, is open by definition, but this quality could be observed in different concrete 
instantiations. 1) Local net structures with free communicative action inside them - but with fixed external borders - are examples of net of the first type [3]. Various secret decentralized communities can be considered as examples of such type of net organization. 2) Delocalized nets represent the second type of nets. An instance of such second type of nets are global net organizations in society, and contemporary commercial enterprises "without borders". The openness of the net has destructive components which could indeed bring to its self-destruction. Such components amount to the net friability and to the static character of the net, and all this causes hierarchy and bureaucracy Speed, as one of the main characteristics of net-interactions, could reduce the costs of the informational transmission. This process could simplify and accelerate the creation of international nets, so providing individuals with the capability of communication "of all to all". The net represents a specific social mechanism of limitation and criticisms to the promotion of new projects. At the same time, the net provides the development and support of initiatives.

The net structure, as a fluid structure, is different from the stiff hierarchical structure, first of all, with respect to the following points. It displays a constrained and uninterrupted communication structure and shows a structure of horizontal organization. Besides, it manifests a relevant absence of a single centre and it is based on inclusion, where each member of a net can prove the necessity of the net itself. In addition, it expresses equality and openness of an entrance-exit kind and it is characterized by orientation to results and high effectiveness, together with a capacity to adapt to external and internal factors. Finally, it displays selforganization and self-regulation abilities and low informational resistance. Nets have advantages if compared to traditional hierarchical structures. They decentralize the process of decision making. At the same time, nets incorporate a hierarchical heritage in the form of high levels of constraints for a group. And again nets are free and neutral social forms. Besides, nets are flexible and adaptive types of organizations which could develop together with the surroundings. But net meets difficulties with respect to the following points: coordination of functions; concentration of resources on certain aims; control of difficult operations out of the boundaries of the net [4].

J. Podolny and J. Karen describe the net changes which occur in the inner structure of traditional hierarchical firms and organizations considered in the most recent years.

- The first difference between net forms of organization and traditional forms of organization is ethical - it is value-oriented for the members of the net.

- The central element of net forms of organization is a "spirit of goodwill" which is based on forms of representation that exploit the medium of votes instead of violent processes of decision making, and which are a guarantee for high levels of trust between the members of the net.

- Net organization is based on norms of mutual respect.
- Members of the net organization create a moral community in which confident activities prevail. Thus net forms of governance could provide best education, best control on the environment and best economical results.

Theorists investigate globalization as a process of global networks formation, picking out several nets of social communication in the actual world:

- national nets, created by national states that put our lives under a system of law local nets, defining direct social relations and control;

- $\quad$ international nets, that define several international processes, including interstate agreements on problems of migration, transportation systems, communication, taxes, etc.;

- transnational nets, which should be seen to be independent from nets controlled by national states;

- $\quad$ global nets, occupying the globe.

Informational nets change the actual production, consumption, power, experience and culture on a great scale. Global net organizations represent a new type of net structure based on networks of political institutions and international, national, local institutions of decision making. Individualization and decentralization are the opposites with respect to the socialization of work, vertical integration and big production, which characterize industrial society forms of organization and interaction. Modern net organizations guarantee the flexibility of firms, individuals, countries in conditions of globalization [5].

\section{Soft Globalization}

In spite of several fruitful findings concerning the investigations of the process of globalization, many theories show a common shortcoming: they study the problem only at the empirical level, thus putting into focus only one side of the globalization process - viz. the material side, which leads to the formation of the Empire. The appeal to the empirical level alone is one of the main sources of misunderstanding of the real nature of the problem. The concept of soft globalization is built on the attempt to develop a philosophical analysis of this phenomenon, by searching the means for an intensification of the analysis of the problem, and by stressing the importance of investigating the spiritual dimension of globalization, which could prompt the formation of a global democracy. This innovation is implemented by studying the globalization process in connection with the evolution of civilizations.

Civilization is one of the world structures, which contains the information about the material and mental form of humans' activities [6]. The development of the world civilizations has an irregular character which could be described, at the phenomenal level, in the stages of appearance, growth and disappearance of the civilizations themselves. Civilization, as a complicated structure, has a meta-stable steadiness. In order to keep its integrity, so that periodically to overcome the tendency to stochastic disintegration, civilization should exist in regimes able to slow down the processes and 
restore the general temp of the substructures of development. Under this respect, it is better to consider a globalization and de-globalization function as social regulators for the equilibrium of the energetic balanceimbalance of civilization. The process of regulation of civilization's balance-imbalance, through the processes of globalization-de-globalization, embodies the disposition of a system to reach a stable equilibrium. Such view has provided the opportunity to produce new interpretations about the history of human civilization as a process of self-organization of human communities in time and space.

The motivating force behind civilization's development is an accumulated energy, which consists of material and immaterial complexes, depending on consuming energy obtained from natural resources within occupied territory. Civilization development is connected with territoriality as a basis of civilization flourishing. The process of civilization's accumulation of new territories in forms of expansions, displacement of people, wars, and conquests leads to the appearance of an oligarchic tendency, which leads to unification of the local communities into the universal organization with centralized direction (globalization). Thus, material globalization, historically, especially in modern times, occurs in the form of the Empire. The local tendencies of the communities' development (localization) are opposite to the process of globalization when it brings about the disintegration of the global communities (disintegration of great Empires in history of culture, disintegration of the Soviet Union in modern times). Globalization and localization represent the tendencies of unity and disintegration of communities simultaneously coexisting in the history of civilization given the tendency of a pole to dominate.

The author of this article argues that globalization (in spite of the existing interpretations of this phenomenon as universalism, interculturalism, multiculturalism, etc.) represents the social response to the tendencies of civilization's parceling out, or disintegrating, or even getting destructive [7]. Globalization is periodically replaced by the alternative tendency - localization, which embodies the social response to the tendencies of unification: unity of communities under the aegis of the single dominating community. Therefore, globalization and localization carry out the function of a social regulator of 'balance-imbalance' concerning the civilization's development. The development of Ancient Rome, for example, can be considered as a manifestation of a kind of material globalization in the history of civilization. Ancient Rome kept inside itself the highest levels of progress of Ancient Greece, the Ancient Middle East and so on, and thanks to Ancient Rome's influence over the world the development of human civilization as a whole moved forward greatly in this period. But the material orientation of the process of globalization brought about the crash of the Roman Empire. The next significant fluctuation of globalization can be observed now, when the western civilization moves forward the development of a human civilization as a whole. But in order for this process to be successful, globalization must assume not only a material shape, but also a mental character, a character oriented towards the creation of new norms of global democratic politics formation.

\section{Conclusion}

The author has critically examined, in this paper, the main approaches concerning the investigation of social, political, informational and net processes of globalization. All these aspects characterize the process of globalization so that to make it a mainly material process, which brings one close to the existence of some sort of the Empire. The author's own hunch is that all such approaches are important. All of them highlight some relevant and fruitful scientific findings about the phenomenon of globalization and its contemporary occurrence. For example, the process of globalization is evaluated as a universal, multicultural and trans-cultural process or the role of globalization for the formation of a global space consists in preserving differentiation with respect to production, deterritorialization, world politics and finance. In addition, it can be a transformation of heterogeneous areas of social activity in the global era or the analysis of global legal and political reforms or the description of crucial cases about the technology of the global net, etcetera. Nevertheless, the author's main purpose in this article has been to argue that solely the globalization, which is understood in a mental form, could be successful in the end.

Evolution of civilization in the form of the Empire caused by material globalization will not last long, for this process determines the destruction of civilization itself. New technologies will bring together and then push away differences between globalized communities, thus creating an unstable development for the civilization. In the process of soft globalization, nonrepressive mechanisms of social regulation alternative to the Empire could instead be realized. Given the conditions of contemporary multiethnic and multicultural world, globalization processes should be oriented gradually to the leveling of all globalized communities on the basis of the quintessence of the spiritual formation, which leads to a new type of democracy formation. And this implies, among the other things, the elimination of the opposition between Western liberal societies and Eastern fundamentalist societies.

Fundamentalist societies are burdened with religious extremism, which is expression of direct attempts to meet the basic needs of human existence. These attempts are based on the principle of survival as a natural principle of self-preservation for human beings. Elimination of the opposition between liberal and fundamentalist societies can be achieved on the basis of a new type of spiritual formation, which escapes and perhaps solves the problem of human survival - such process is oriented toward the pure material side of the life of the human beings. Within the boundaries of a new type of spirituality, a new democratic politics permitting a dialogue for distinct religious confessions and the ground for their consensus could be achieved. As a final remark, the author thinks that only in this case a society 
decision-making process and the content of its law could incorporate solutions to the conflicts of belief and values among the population, and this could appear because of a new human being, who is not burdened by a destructive religious extremism. Given all this, one could really see the appearance of a democratic type of politics, expression of some form of freedom (in the Kantian's sense) as a combination of the conditions, under which tyranny of one person can be balanced by the tyranny of another person, according to a principle of liberty common to such persons. Soft globalization gives the opportunity to avoid imperialistic desires in world politics to any political subject.

\section{Acknowledgment}

The author wishes to thank Tomsk Polytechnic University for a chance to participate in this highly beneficial research forum.

\section{References}

1. Globalization (2011) From http://www.seop.leeds.ac.uk/archives/spr2011/entrie s/globalization/.

2. C. Eschle, Constructing the 'Anti-Globalization' Movement. In: Critical Theories, International Relations and the 'Anti- Globalization' Movement: the Politics of Global Resistance (London and New York: Routledge, 2005)

3. J. Habermas, The Postnational Constellation: Political Essays (Cambridge, MA: MIT Press, 2001)

4. D. Held, Democracy and the Global Order: From the Modern State to Cosmopolitan Governance (Stanford: Stanford University Press, 1995)

5. D. Held, and A. McGrew, D. Goldblatt, J. Perraton, Global Transformations: Politics, Economics and Culture (Stanford: Stanford University Press, 1999)

6. I. B. Ardashkin, Proc. Soc. and Beh. Sc., 166 (2015).

7. L.A. Korobeynikova, Proc. Soc. and Beh. Sc., 166 (2015). 